\title{
A LINGUAGEM REGIONAL POPULAR DE ARIANO SUASSUNA NA OBRA UMA MULHER VESTIDA DE SOL
}

\author{
Uélida Dantas de Oliveira \\ Mestre em Letras pela Universidade Federal da Paraíba (PPGL/UFPB) \\ uelida1114@hotmail.com
}

\section{RESUMO}

$\mathrm{O}$ artigo em questão tem como propósito apresentar uma análise da linguagem regional do escritor Ariano Suassuna, realizando leitura da obra intitulada Uma mulher vestida de sol, buscando selecionar palavras ou expressões de cunho natural do léxico regional nordestino, com o objetivo de expor por meio de um vocabulário as escolhas lexicais do escritor presentes em determinada obra. Devido à riqueza de expressividade linguística de Ariano Suassuna, propomos a análise do livro Uma mulher vestida de sol, com enfoque na linguagem do escritor. Por se tratar de um estudo voltado para a linguagem do autor predominante na obra, discorremos sobre a teoria do léxico e, com relação ao falar regional, fez-se necessária uma breve discussão em torno das variações linguísticas, com ênfase na variação diatópica. Para a elaboração do vocabulário, foi necessária a utilização de dicionários regionais e da língua portuguesa, para constatarmos os significados das expressões selecionadas.

Palavras-chave: linguagem regional, Ariano Suassuna, vocabulário.

\section{ABSTRACT}

This article presents an analysis of the regional language used by writer Ariano Suassuna in A woman dressed in sunshine, seeking to select words or expressions natural to the Brazilian northeastern regional lexicon, aiming at exposing through vocabulary the writer's lexical choices in a particular work. Due to the richness of Ariano Suassuna's linguistic expressiveness, we propose the analysis of A woman dressed in sunshine directed towards the language used by the writer. Since this is a study focused on the language of the author upon the work, we discuss the lexical theory and a brief discussion about linguistic variations made itself necessary concerning regional speech, with emphasis on diatopic variation. For the elaboration of the vocabulary, it was necessary to use regional and Portuguese language dictionaries to verify the meanings of the expressions selected.

Keywords: regional language, Ariano Suassuna, vocabulary. 


\section{Considerações iniciais}

A língua transporta um sistema de signos que são vinculados a relações sociais e culturais, considerando o fato da comunicação exercida pelo homem geralmente ocorrer por meio de palavras. Esses signos lexicais transmitem uma representação de dados sensoriais provenientes da experiência de um grupo, no qual, apresentam-se um sistema lexical estruturado por categorias lexicais que exibem a percepção da realidade vivenciada pelo grupo sendo refletida em sua linguagem. Conforme discorre Biderman (2001):

O Léxico de qualquer língua constitui um vasto universo de limites imprecisos e indefinidos. Abrange todo o universo conceptual dessa língua. Qualquer sistema léxico é a somatória de toda a experiência acumulada de uma sociedade e do acervo da sua cultura através das idades. Os membros dessa sociedade funcionam como sujeitos agentes, no processo de perpetuação e reelaboração contínua do Léxico da sua língua (BIDERMAN, 2001, p. 179).

No que se refere aos estudos linguísticos, o léxico é o elemento capaz de relacionar homem, sociedade e cultura. Essa relação entre o homem e a sociedade em que vive transpõe-se para o seu modo de falar e usar o léxico para comunicar-se individualmente ou em grupo, transparecendo em suas escolhas lexicais aspectos culturais da sociedade da qual se faz membro. Segundo Villalva e Silvestre (2014):

O Léxico de cada falante, que é também chamado de Léxico mental, depende da sua apropriação dos estímulos lexicais a que é exposto, e, portanto, variará muito em função da sua experiência linguística individual, do que ouve, do que lê, do que fala e do que escreve (VILLALVA; SILVESTRE, 2014, p. 23). 
O léxico de uma língua está em um processo constante de mudanças e criações, pois, com o passar do tempo, algumas palavras deixam de ser usadas, e outras vão surgindo, ganhando sentido para a comunidade ou região. Percebe-se que, com esses movimentos na língua de determinado grupo, se torna notória a relação existente entre o contexto social e o cultural, sendo mediadores de significados entre o homem e o mundo. Para Barbosa (1993, p. 158), língua, sociedade e cultura são "termos indissociáveis, já que interagem continuamente e constituem, na verdade, um único processo complexo".

Diante do exposto, analisaremos a obra Uma mulher vestida de sol, do escritor nordestino Ariano Suassuna, visando evidenciar o léxico da comunidade à qual ele pertenceu, e organizar um vocabulário através da linguagem apresentada na obra, que retrata a cultura e a intervenção social em determinada região.

\section{Ariano Suassuna: dados biográficos}

Ariano Vilar Suassuna nasceu em 16 de junho de 1927, na Paraíba, e faleceu em 23 de julho de 2014 em Pernambuco, ambos os estados do nordeste brasileiro, lugares onde o escritor passou sua vida e construiu suas histórias.

O consagrado escritor das obras Auto da Compadecida e Romance d'a Pedra do Reino, além de idealizador do movimento armorial, foi um excelso defensor da cultura nordestina no Brasil.

Ariano Suassuna é autor de muitas obras que expressam a grandeza da sua visão de mundo e da cultura do nordeste brasileiro, tais como: Uma Mulher Vestida de Sol (1947), O Santo e a Porca (1957), Fernando e Isaura (1956) e O Casamento Suspeitoso (1957), entre outras. 
Com formação acadêmica em Direito pela Faculdade de Direito do Recife, porém apaixonado pela literatura e pelo teatro, o escritor deixou de lado a advocacia e dedicouse às suas obras e à profissão de professor na Universidade Federal de Pernambuco, onde ministrou a disciplina de Estética Literária.

Membro das Academias Paraibana e Pernambucana de Letras, Ariano Suassuna também ocupou a cadeira de número 32 da Academia Brasileira de Letras em 1990. Com sua inserção em âmbitos que enfatizam a cultura, a literatura e as artes, o escritor foi nomeado Secretário da Cultura de Pernambuco e exerceu o cargo entre os anos de 1994 e 1998.

\section{Uma mulher vestida de sol}

Escrita pelo dramaturgo paraibano Ariano Suassuna no ano de 1947, a obra em estudo é inspirada no romanceiro nordestino e aborda temáticas como honra, sangue, família, incesto e vingança.

Considerada a primeira grande tragédia produzida no nordeste brasileiro, a obra apresenta uma diversidade de elementos regionalistas com a presença de traços cômicos que o escritor inseriu no enredo da tragédia.

Uma mulher vestida de sol relata a história de amor proibido dos personagens Rosa e Francisco, que são primos, e, além disso, estão envolvidos numa disputa gerada por seus pais, que se tornaram inimigos mortais e brigam por posse de terras.

Os pais de Francisco e Rosa são personagens que demonstram sentimentos e personalidades bem distintos, enquanto Joaquim Maranhão, pai da jovem Rosa, é cruel e 
muito violento; Antônio Rodrigues, pai de Francisco, expressa sentimentos de justiça e sensatez, sendo visto como uma pessoa do bem.

Esse conflito pela posse de terras representa o conflito entre o bem e o mal, que representados por Joaquim Maranhão e Antônio Rodrigues tecem o enredo juntamente com personagens que dão força a essa disputa, como os parentes pobres de Joaquim Maranhão, que por passarem muita necessidade trabalham para o fazendeiro, e também a exemplo dos capangas Caetano e Manuel que trabalham para Antônio Rodrigues. Vale frisar que, em toda a história, encontramos a presença da religiosidade nordestina representada pelo beato Cícero.

Diante dessa história, focalizamos a descrição da cultura regional nordestina, no léxico da região transmitido pelo falar regional dos personagens de Ariano Suassuna, e elaboramos o vocabulário baseado nas expressões contidas na obra.

\section{Variações linguísticas: um enfoque na variação diatópica}

Atendo-se ao fato do estudo em questão ter por objetivo a elaboração de um vocabulário da linguagem regional do escritor Ariano Suassuna na obra Uma mulher vestida de sol, é necessário abordarmos a teoria da variação linguística, especificamente a variação diatópica em se tratando que o enfoque é o falar regional.

As variações linguísticas são processos que acontecem na língua de uma comunidade, região ou pessoa, provenientes de alguns fatores que geram mudanças linguísticas, proporcionando distinções no vocabulário de grupos e indivíduos. Como acrescenta Saussure (1996, p. 221): "é um fenômeno de uma língua que sofre variação ao 
longo do tempo, do espaço geográfico, de espaço ou estrutura social, da situação ou contexto de uso".

Quanto à variação diatópica, a mesma tem função de apresentar a diferença linguística existente de região para região, ou seja, um mesmo objeto ou situação é nomeado de forma distinta em cada região geográfica do país. De acordo com Mussalin e Bentes (2006, p. 34), “A variação geográfica ou diatópica está relacionada às diferenças linguísticas distribuídas no espaço físico, observáveis entre falantes de origens geográficas distintas".

A variação diatópica predomina na obra de Ariano Suassuna por se tratar de um autor do regionalismo brasileiro, e, através desse fenômeno linguístico, ele apresenta sentimentos e situações sociais por meio de uma linguagem típica e rica em características regionais nordestinas. Segundo Santana (2012, p. 62), “A variável diatópica (e suas implicações de ordem social, econômica e cultural) influencia a variação linguística e pode ser considerada como um dos diversos fatores que atuam na mudança de uma língua”.

É possível constatar que, em uma mesma região, se formam comunidades com costumes linguísticos diferentes, que demonstram a influência da região geográfica no seu vocabulário, mas que contam também com fatores políticos e econômicos na estruturação do seu léxico.

Em síntese, compreende-se que a variação diatópica vai exibir a diferença na pronúncia, no vocabulário e na estrutura sintática existente no léxico das regiões. $\mathrm{Na}$ seção seguinte, temos o vocabulário regional que organizamos com a linguagem apresentada por Ariano Suassuna no livro Uma mulher vestida de sol. 


\section{Vocabulário de Ariano Suassuna na obra Uma mulher vestida de sol}

Para a elaboração do vocabulário alguns critérios foram seguidos, são eles: primeiramente, as palavras são apresentadas em ordem alfabética, com grafia maiúscula e em negrito. Em seguida, a classe gramatical pertencente e os significados de acordo com o que verificamos nos dicionários de língua portuguesa e regionais nordestinos. Por fim, os exemplos de acordo com a obra analisada, que aparecerá identificada pelas siglas A.S. (Ariano Suassuna) e U.M.V.S (Uma mulher vestida de sol) e destacadas em negrito. Vejamos:

A TERRA TREME NA VISTA: Sintagma Verbal. Expressa uma sensação de desconforto na visão.

Tremer: v. 1. Agitar(-se) fisicamente por medo, forte emoção ou fenômeno externo. 2. Provocar ou sofrer grande abalo. Vista: sf. 1. Visão 2. Olho. 3. O que é visto, cena. 4. Paisagem, panorama. (HOUAISS, 2012, p. 770 e 806)

"O sol está vermelho e a terra treme na vista." (U.M.V.S, 2011, p. 42)

AZEITAR: Verbo. Expressa o sentido de realizar algo.

Azeitar: Apressar, turbinar: "É melhor azeitar as canelas e correr antes que o pau quebre." (NAVARRO, 2004, p. 45)

"Camarada, pode azeitar o rifle, porque o barulho vai começar hoje à noite." (U.M.V.S, 2011, p. 88)

BARRO ACORDADO: Substantivo Masculino. Refere-se ao barro úmido. 
Barro: sm. 1. Terra usada para fazer tijolos, telhas, etc; argila. (HOUAISS, 2012, p.97)

"Na cacimba, quanto mais cedo melhor. Eu desço até a água, sentindo o cheiro de barro acordado." (U.M.V.S, 2011, p.55)

BOTAR: Verbo. Ato de colocar ou pôr.

Botar: V. Substitui com muita frequência o verbo pôr: "Bote o jantar", "a galinha botou um ovo", "bote meu nome no papel". (CABRAL, 1982, p.128)

"Francisco não bota mais os pés na terra que você pisar." (U.M.V.S, 2011, p. 68)

BRABO: Adjetivo. Sentido de braveza.

Brabo: Adj. 1. Bravo, arisco, não domado (animal). 2. Grosseiro, estouvado, zangado. 3. Valente, perverso. (CABRAL, 1982, p.132)

"Sei por que você não me quer, por que vive pelos cantos, pelos matos, feito um bicho brabo, a ponto de que o povo já começou a falar." (U.M.V.S, 2011, p. 49)

CACIMBA: Substantivo feminino. Referente a um poço ou compartimento para armazenar água.

Cacimba: SF. 1. Poço ou cisterna de regular ou grande profundidade, com ou sem paredes de alvenaria. 2. Escavação no leito seco dos rios, para juntar águas rasas do aluvial. (CABRAL, 1982, p.157)

"Você vai para cacimba." (U.M.V.S, 2011, p. 54)

CANGAÇO: Substantivo Masculino. Expressão referente ao modo de vida do cangaceiro, pessoa que vive no sertão como salteador. 
Cangaço: Sm. Troços, trastes, cacarecos, cangaçada, mucumbu. 2. Pendúculos e restos de folhas de coqueiro, tibacas, catemba. 3. Tudo o que acompanha o cangaceiro nas suas jornadas: roupa, arma, munição, alimento. Ver andar no cangaço. 4. Vida de bandido, de marginal, de acordo com Leonardo Mota em Cantadores. (NAVARRO, 2004, p. 93)

"E se ao menos ele gostasse de você! E se ele está no cangaço mesmo, como dizem?" (U.M.V.S, 2011, p. 50)

ENCARNADO: Adjetivo. Tem sentido de manchado.

Encarnado: Adj. Diz-se da imagem ou "santo" feito, recomposto ou consertado "Deixaram muitas coisas encarnadas nas igrejas e capelas." Encardido: Adj. Sujo ou manchado, por ter sido mal lavado e conservado nesse estado. (CABRAL, 1982, p. 328)

"Aqui só manda a vontade dele! Pior é que vejo tudo encarnado para frente, agora com Rosa." (U.M.V.S, 2011, p. 65)

MEUS BENDITOS E EXCELÊNCIAS: Substantivo Masculino. Refere-se a um canto religioso que expressa sentimentos como sofrimento e lamento.

Bendito: Sm. Cantar bendito. Ver este verbete (Cabral, 1982, p. 107). Cantar bendito sofrer. (Expressão pouco usada atualmente). “Cantar bendito é a expressão matuta que significa sofrer, padecer" (OAP 459). (CABRAL, 1982, p. 180)

"Vamos ver, vamos ver. Talvez, seja eu que cante, no seu, meus benditos e excelências. Ainda hei de viver muito tempo." (U.M.V.S, 2011, p. 56)

MEUS CABRAS: Substantivo Masculino. A expressão é usada para referir-se a indivíduos que agem como capangas ou cangaceiros. 
Cabra: Sm. 1.Indivíduo de baixa condição. 2. Indivíduo ruim, safado, imprestável, vagabundo. 3. Capanga, criminoso, pistoleiro. Membro subalterno de grupo de cangaceiros. 4. Qualquer indivíduo. Referência a determinada pessoa. (CABRAL, 1982, p. 150)

"No dia em que eu desarmar meus cabras, ele bota minha cerca abaixo. E nesse mesmo dia morre, porque eu mato." (U.M.V.S, 2011, p. 68)

PEGA NÃO PEGA: Substantivo Masculino. Ato de brigar ou discutir.

Pega: SM. Questiúncula, discussão, briga ou luta. Pega-pega: SM. Briga, discussão, bateboca. (CABRAL, 1982, p. 586-587)

"Aqui a briga está pega não pega!" (U.M.V.S, 2011, p. 55)

SANGUE RUIM: Adjetivo. Expressão referente a pessoas que agem com maldade.

Sangue ruim: Adj. 1. Sangue impuro, portador de sífilis. 2. Mau gênio. 3. Má sorte em empreendimentos, azarento. (CABRAL, 1982, p. 677)

"Não se meta com aquele povo não, meu filho. É triste dizer isso do próprio irmão, mas aquilo é gente de sangue ruim." (U.M.V.S, 2011, p. 114)

\section{Considerações finais}

O estudo realizado sobre a obra Uma mulher vestida de sol, do escritor Ariano Suassuna, apresentou em seu resultado a linguagem como produto cultural, transparecendo o modo de pensar e de sentir de uma determinada comunidade, que por meio de seu vocabulário expressa costumes e tradições de uma região. 
Por meio do seu léxico, pudemos acessar parte de sua cultura, conhecer a estrutura social e econômica, e precisamente a estrutura geográfica. O autor faz uso do léxico regional popular nordestino com expressões características do povo sertanejo do nordeste brasileiro, o que faz com que enxerguemos a influência da sociedade e da cultura na linguagem presente em sua obra, remetendo a uma comunidade geográfica representada pelo escritor, formando a tríade língua-cultura-sociedade.

\section{Referências}

BARBOSA, M. A. O léxico e a produção da cultura: elementos semânticos. I Encontro de Estudos Linguísticos de Assis. Anais. Assis, SP: UNESP, 1993.

BIDERMAN, M. T. C. As ciências do léxico. In: OLIVEIRA, A. M. P. P; ISQUERDO, A. N. (Orgs.). As ciências do léxico: lexicologia, lexicografia, terminologia. v. 1. Campo Grande: Ed. UFMS, 2001. p. 153-166.

CABRAL, T. Novo dicionário de termos e expressões populares. Fortaleza: UFC, 1982.

HOUAISS, A. Dicionário da língua portuguesa. Rio de Janeiro: Objetiva, 2012.

MUSSALIN, F; BENTES, A. C. Introdução à Linguística: domínios e fronteiras. v. 1. São Paulo: Contexto, 2006.

NAVARRO, F. Dicionário do nordeste: 5000 palavras e expressões. São Paulo: Estação Liberdade, 2004.

SANTANA, A. P. A síncope revisitada: análise com base no corpus do ALiMA. In: Littera Online. São Luís: FL - UFMA, n. 5, 2012. Disponível em: <http://www.periodicoseletronicos.ufma.br/index.php/littera/article/view/1266/992>. Acesso em: 23 jan. 2018. p. 50-68.

SAUSSURE, F. Curso de linguística geral. Tradução de Antônio Chelini, José Paulo Paes e Izidoro Blikstein. 27 ed. São Paulo: Cultrix, 1996. 
SUASSUNA, A. Uma mulher vestida de sol. Rio de Janeiro: José Olympio, 2011.

VILLALVA, A; SILVESTRE, J. P. Introdução ao estudo do léxico: descrição e análise do Português. Rio de Janeiro: Vozes, 2014.

Recebido em 8 de março de 2018.

Aceito em 26 de abril de 2018. 